\title{
Inovações em EAD: Modelo pedagógico e reconstruções conceituais em uma formação de professores
}

\author{
Rosane Aragón ${ }^{1}$, Crediné Silva de Menezes ${ }^{2,3}$ \\ ${ }^{1}$ Programa de Pós-graduação em Educação (PPGEDU/UFRGS), Porto Alegre, RS, \\ Brasil \\ ${ }^{2}$ Faculdade de Educação (FACED/UFRGS), Porto Alegre, RS, Brasil \\ 3.Programa de Pós-graduação em Informática (PPGI/UFES), Vitória, ES, Brasil \\ rosane.aragondufrgs.br, credinedgmail.com
}

\begin{abstract}
This study seeks to analyze the relationships between the characteristics of the model for teacher formation, in a distance learning modality course and the grasp of consciousness of the teacher-students considering their written productions. Data were treated using the Statistical Implicative Analisys that enables identify qualitative relationships existing in a large amount of data. The results confirm the suitability of the design features of the course to the desired formation, highlighting the features of the constructivist-interactionist course as well as the intensive use of technology.
\end{abstract}

Resumo. Este estudo busca analisar as relações entre as características do modelo de formação do curso de Licenciatura em Pedagogia, na modalidade a distância e as tomadas de consciência das professoras-alunas a partir de suas manifestações escritas. Os dados foram tratados segundo a Análise Estatística Implicativa que possibilita identificar as relações qualitativas existentes, em uma grande quantidade de dados. Os resultados confirmam a adequação das características do modelo do curso para a formação pretendida, destacando-se as características construtivistas- interacionistas do curso, bem como o uso intensivo das tecnologias.

\section{Introdução}

$\mathrm{Na}$ perspectiva de contribuir com a concepção de novos modelos para a Educação a Distância (EAD), realizamos um projeto institucional de Educação Superior, voltado para a formação de professores em serviço, baseado numa concepção curricular interdisciplinar, em uma metodologia interacionista-problematizadora e no uso intensivo das Tecnologias de Informação e Comunicação como ferramenta de suporte a formação de redes de aprendizagem. Com a aplicação desse modelo buscamos nos aproximar, cada vez mais, de uma educação sem distâncias, onde o tempo e as diferentes localizações geográficas não tirem dos estudantes a possibilidade do diálogo.

No presente artigo apresentamos os resultados de uma investigação baseada nas produções de estudantes do curso, registradas e disponíveis nos portfólios de aprendizagem (webfólio). O trabalho busca identificar as relações entre o modelo de formação proposto, considerando as suas características construtivistas-interacionistas e seus efeitos sobre as mudanças nas concepções pedagógica, focalizando as tomadas de consciência (descobertas, compreensões) relacionadas à formação vivenciada no curso e 
a reconstrução/recriação de formas de atuação nos espaços de docência das professorasalunas.

O artigo está organizado da seguinte forma: na seção 2 apresentamos o contexto onde o estudo foi realizado, na seção 3 é feita uma breve apresentação do referencial teórico considerado para análise, a seção 4 é dedicada ao desenho da pesquisa, já na seção 5 faz-se a análise dos dados a partir das arvores e grafos obtidos com o uso do CHIC (uma ferramenta de apoio à análise de dados), por fim, na seção 6, realizamos nossas considerações sobre o que se pode concluir com este estudo

\section{O Curso de Licenciatura em Pedagogia na modalidade a distância}

Para atender uma demanda de formação superior inicial de professores da rede pública, em serviço, a Faculdade de Educação da Universidade Federal do Rio Grande do Sul ofereceu um curso de Licenciatura em Pedagogia, na modalidade a distância, no período de 2006/2 a 2010/2. O curso contou com um ingresso de 400 professores da rede pública de municípios do Estado do Rio Grande do Sul, dos quais 330 foram diplomados. O curso teve como suporte presencial os polos instalados em 5 municípios. Cerca de $98 \%$ dos estudantes do curso eram do sexo feminino, o que nos leva a tratá-los neste texto por professoras-alunas.

\subsection{Organização Curricular}

Seguindo as orientações resultantes de estudos recentes investimos na construção de um currículo de natureza interdisciplinar. Buscou-se a aproximação das disciplinas clássicas, formando campos de estudos, que foram denominados de interdisciplinas. Os grandes temas da formação de professores deram suporte a formação de eixos, onde as interdisciplinas foram agrupadas (Bordas et all, 2005). Permeando todo o curso, foi concebida a interdisciplina Seminário Integrador, que tinha dois papéis centrais no desenvolvimento do curso: i) apoiar a interação entre as disciplinas de cada eixo e entre os diversos eixos, e ii) acompanhar o desenvolvimento das professoras-alunas do inicio ao final do curso.

\subsection{Desenvolvimento do Curso}

O desenvolvimento do curso teve como base a metodologia interacionistaproblematizadora, requerendo, portanto um constante diálogo entre professoras-alunas, tutores e professores-formadores. O tamanho das turmas foi estabelecido de forma que cada 80 professoras-alunas tivessem um professor e um ou dois tutores para orientá-las em cada interdisciplina. As atividades de cada interdisciplina seguiram um planejamento integrado com as demais interdisciplinas com o apoio articulador do seminário integrador.

Preferencialmente foram realizadas atividades que serviram de ponto de partida para o trabalho nas diversas interdisciplinas e estas, tinham como fundamento principal a articulação teoria-prática. Assim, em geral, as atividades partiam do trabalho do professor em sua sala de aula buscando o suporte teórico para analisar e ressignificar suas práticas.

Periodicamente foram realizados encontros presenciais com a presença dos professores-formadores e tutores das interdisciplinas e, as interações prosseguiam através de atividades cooperativas em ambientes virtuais e encontros síncronos com professores-formadores e tutores-sede, segundo as necessidades de cada professoraaluna. 


\subsection{Acompanhamento Individual e Avaliação das Aprendizagens}

Cada professora-aluna foi acompanhada de forma individualizada do inicio ao final do curso pela equipe do Seminário Integrador em parceria com as equipe de tutores-polo e das interdisciplinas de cada eixo. O suporte principal deste acompanhamento foi um portfolio na web (webfólio), no qual as professoras-alunas registravam e refletiam sobre as suas aprendizagens, compondo assim um excelente material para subsidiar o acompanhamento e a avaliação.

Ao final de cada semestre, com o apoio dessas postagens e tendo por base um proposta de reflexão integrada, as professoras-alunas construíam um documento de avaliação reflexiva a ser apresentado oralmente no evento Workshop de Avaliação.

\subsection{A importância do Suporte Computacional para implementação do modelo de curso}

Diferente de outros modelos de $\mathrm{EaD}$, ainda hoje praticados, o que adotamos está fortemente embasado no diálogo entre os atores do curso (professoras-alunas, formadores e tutores). Desta forma, foi necessário um uso intensivo dos ambientes virtuais com ênfase na autoria (web 2.0) e ferramentas de comunicação. $O$ desenvolvimento de atividades cooperativas foi preferencialmente apoiado por um ambiente wiki, as comunicações online foram realizadas através de ferramentas populares de troca de mensagens e, o acompanhamento individualizado usando ferramentas do tipo blog.

Com uso das ferramentas de comunicação o atendimento individual deu-se, sem que houvesse a necessidade de deslocamentos, sem filas de espera. Navegando pelos ambientes compartilhados, as professoras-alunas puderam conhecer os trabalhos produzidos pelos diversos colegas, facilitando assim a identificação de trabalhos afins, as dificuldades comuns e, a partir dai, dando inicio a profícuas cooperações, independentemente das atividades curriculares. A realização de estratégias pedagógicas mais efetivas puderam ser implementadas, assim como a identificação dos estudantes que requeriam apoio diferenciado tiveram fortes influências nas aprendizagens das professoras-alunas como se pode constatar pelas postagens em seus webfólios.

\section{A tomada de consciência}

A passagem de elementos que compõem o inconsciente cognitivo para o nível consciente implica em uma reconstrução, em um plano superior (consciente) do que já está organizado de outra forma no plano inconsciente. Dito de outra forma, o processo de tomada de consciência não ocorre de maneira abrupta, como se fosse uma iluminação repentina (insight), mas ocorre a partir de construções e reconstruções graduais que constituem as conceituações. Ou seja, a tomada de consciência de um esquema de ação o transforma em um conceito, essa consistindo em uma conceituação.

O que leva a tomada de consciência? Para Piaget (1977) a tomada de consciência é desencadeada pelas insuficiências das regulações automáticas que levam a busca de novos meios mediante regulações mais ativas que pressupõem escolhas deliberadas, o que supõe algum nível de consciência

Considerando a perspectiva da passagem de uma ação material (saber fazer) para o pensamento (interiorização das ações), a lei geral que resultou dos estudos piagetianos mostra que a tomada de consciência procede da periferia (objetivos e resultados das ações) e se orienta em direção às regiões centrais da ação com o reconhecimento dos 
meios empregados, a descoberta das razões de sua escolha ou de sua modificação em curso, etc.

Desde as tomadas de consciência mais elementares até as conceituações de níveis superiores, a característica mais geral dos estados conscientes é a de exprimir significações transformando os objetos do pensamento e fornecendo um elemento importante que é a determinação das razões. Sem isso os sucessos são fatos sem significado.

Portanto, reformular concepções e práticas pedagógicas de professores também pressupõe uma construção que se dá a partir de tomadas de consciência dos significados que as sustentam e das implicações que delas podem decorrer.

\section{O desenho do estudo}

O estudo considera os registros realizados nos blogs (webfólios), focalizando as tomadas de consciência (descobertas, compreensões) relacionadas à formação vivenciada no curso e a reconstrução/recriação de formas de atuação nos espaços de docência das professoras-alunas.

O espaço dos webfólios foi escolhido por ser um locus privilegiado de relatos de práticas e reflexões das estudantes sobre as suas trajetórias de aprendizagem, incluindo as dificuldades e superações durante o curso. Os textos analisados constituíram uma retrospectiva das trajetórias de aprendizagem durante os nove semestres do curso, realizada pelas professoras-alunas como atividade de fechamento proposta pelo Seminário Integrador. Para o estudo, definimos um dos polos no qual o curso foi desenvolvido e trabalhamos com uma amostra de 12 professoras-alunas $(20 \%$ do número de professoras-alunas do Polo de Alvorada), destacando 161 extratos ${ }^{1 .}$

\subsection{Análise Hierárquica de Semelhanças}

Para o tratamento estatístico dos dados segundo esta abordagem utilizamos o software C.H.I.C (Classification Hierárquique, Implicative et Cohérsive ), desenvolvido por Régis Grás, no Institut de Recherche Mathématique de Rennes (IRMAR) na França (ALMOULOUD, 1992). Este software possibilita uma classificação hierárquica das similaridades; uma análise implicativa e uma classificação coesitiva, que oferecem meios para identificar as relações qualitativas existentes, em uma grande massa de dados. Nesses tipos de análise, o CHIC recebe como entrada uma matriz de presença/ausência das variáveis com respeito a cada sujeito/evento. Os resultados do tratamento estatístico são expressos por um conjunto de correlações entre as variáveis (categorias e subcategorias), em forma de árvore ou grafo.

As árvores geradas apresentam as relações de maior índice de similaridade ou coesão de forma descendente, levando em conta critérios de similaridade e de coesão entre as variáveis. Além disso, oferece para interpretação um grafo que apresenta as interrelações entre as diferentes variáveis.

\subsection{O que mostra o grafo das similaridades e das implicações?}

A análise hierárquica das semelhanças consiste em um método de organização de variáveis segundo sua intersecção, ou seja, ao aparecimento conjunto de dois ou mais indicadores (categorias ou subcategorias). Como critério de semelhança é utilizado no

\footnotetext{
1 Consideramos como extrato cada uma das postagens realizadas pelas professoras-alunas.Foram excluídos, para fins desse estudo, extratos que apresentavam generalidades, poesias, mensagens de felicitações etc.
} 
sentido de vizinhança ou associação. Conforme Grás (1992 e 1999), essa análise busca constituir sobre um conjunto de $\mathrm{N}$ variáveis, partições mais e mais refinadas, de maneira ascendente e apresentada sob a forma de uma "árvore", a partir de um critério de similaridade entre variáveis. O valor máximo dos níveis de similaridade é igual a 1.

No CHIC podemos também obter um grafo que correlaciona as variáveis em estudo na forma de quase-implicações (com índice máximo igual a 1). Isso significa que se a variável a aparece e é verdadeira ou quase verdadeira então a variável b também é verdadeira ou quase verdadeira. Assim, essas relações implicativas ou quase implicativas são instrumentos para evidenciar coocorrências e, por fim, mediante análise, identificar as representações a elas associadas (GRAS, 1997).

\section{Analisando os webfólios}

Leituras exaustivas dos webfólios, à luz da teoria de referência e dos interesses de análise desse estudo, possibilitaram o levantamento de categorias para a análise. Cada extrato foi codificado enquanto presença ou ausência de cada uma das categorias, conforme lista apresentada no Quadro 1.

Quadro 1 - Categorias usadas na classificação das postagens

\begin{tabular}{|l|l|}
\hline APR & Aprendizagens \\
\hline INT & Trabalho realizado nas interdisciplinas \\
\hline CPE & Características do Modelo do Curso (construtivista-interacionista) \\
\hline CQU & Conquistas \\
\hline TIC & Uso de tecnologias \\
\hline PTU & Trabalho dos professores-formadores e tutores \\
\hline TCO & Tomadas de consciência \\
\hline PRA & Práticas em sala de aula (como componente curricular) \\
\hline RTP & Relações entre teoria e prática \\
\hline
\end{tabular}

A categorização deu origem a uma matriz de presenças e ausências que foram submetidas ao software CHIC obtendo-se com isso as uma árvore de similaridades e um grafo de implicações que serão discutidos a seguir.

\subsection{Análise da Árvore de Similaridade}

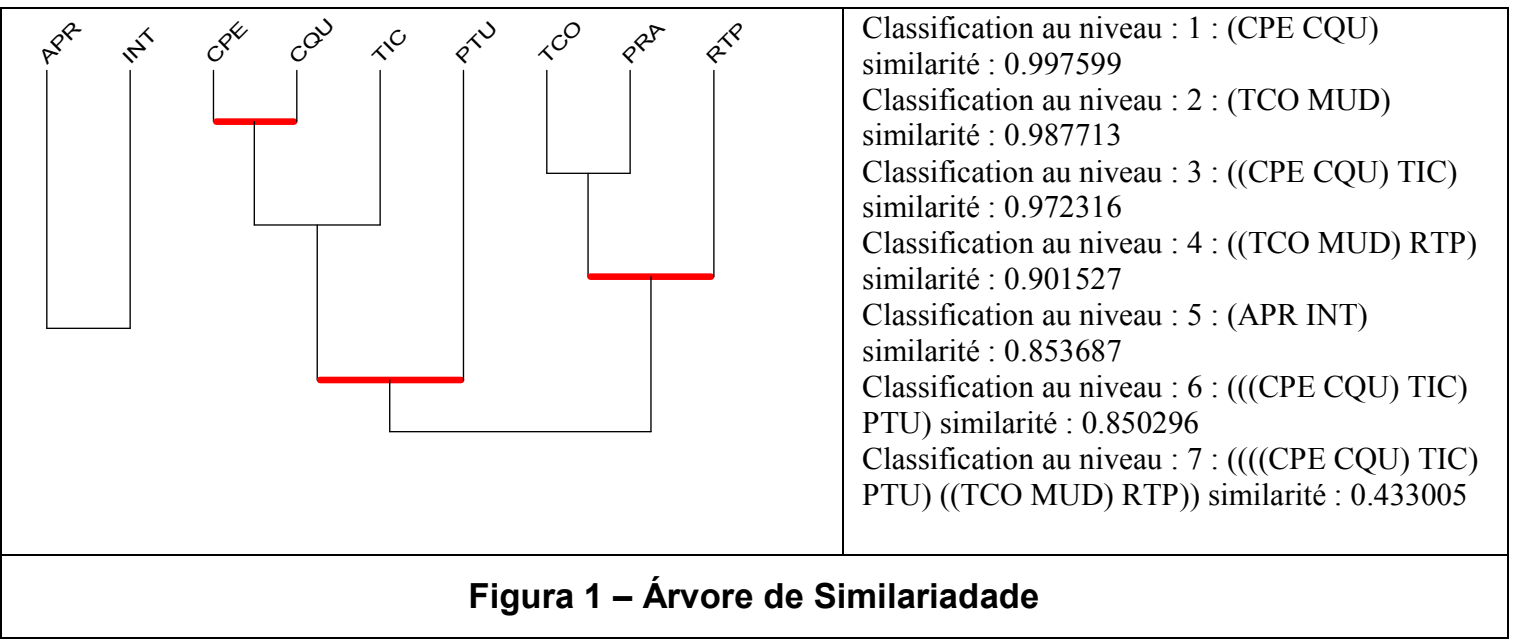


Pelo gráfico das similaridades (Figura 1) podemos observar a proximidade das categorias analisadas. A proximidade das categorias em níveis de similaridade 1 ou bem próximos disso nos permitem fazer um agrupamento dessas categorias em outras categorias mais amplas, denominadas aqui de supracategorias conforme destacamos:

\section{Supracategoria 1: A tomada de consciência das relações entre as conquistas alcançadas (mudanças nas concepções pedagógicas) e as características do modelo de formação}

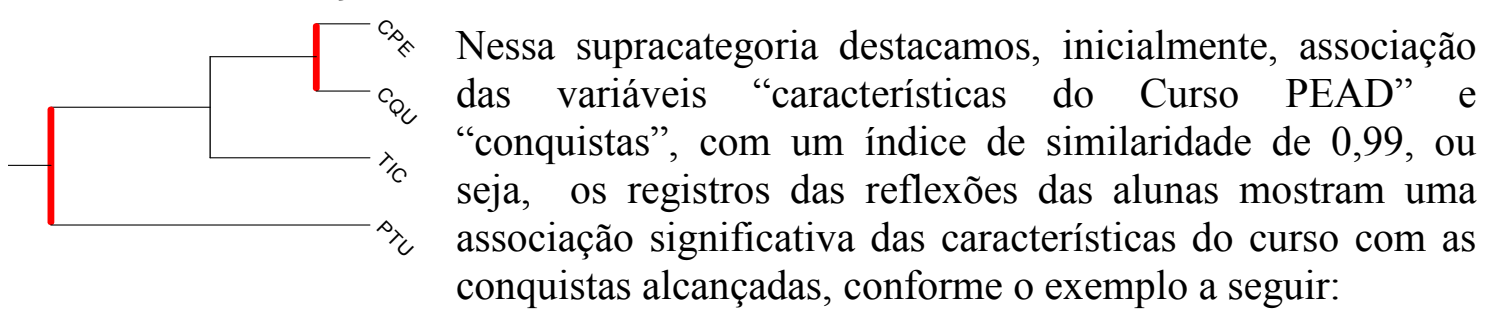

(...) Quando me refiro ao trabalho contextualizado, algo não fragmentado, não consigo deixar de lembrar meu aprendizado no curso, pois considero o mesmo muito importante para embasar de forma positiva essa "nova” educadora que sou hoje. Um fator que considero muito presente durante todo o curso e que constatei novamente através dessa retrospectiva, foi o trabalho interdisciplinar do curso, na qual as teorias se interligavam, onde o aprendizado de uma fortalecia o da outra, isso significa dizer que nosso curso priorizou um trabalho contextualizado, integrado, cooperativo e significativo. (...).Aluna C . Extrato 1

Essa proximidade entre características construtivistas-interacionistas do modelo do curso e as conquistas, enquanto mudanças nas concepções, mantém uma associação significativa com o uso das tecnologias $(0,97)$. Essas relações aparecem nas postagens nos webfólios, mostrando que para as alunas uma das principais conquistas proporcionadas pelo curso está na concepção do uso das tecnologias, não só na situação de alunas de um curso a distância que usa as TICs de forma intensiva, mas também a incorporação das TICs às suas atividades enquanto professoras nas séries iniciais. $\mathrm{O}$ extrato da aluna B exemplifica essa relação.

O que mudou desde então? No dia 13/04/2007 ao ingressar no PEAD, minha escola ainda não tinha uma Oficina Digital, mas logo em seguida, em 22/04 do mesmo ano, nossa OD foi inaugurada. (...) Criei coragem e enfrentei a OD. Foi ótimo, não parei de aproveitar este espaço com meus alunos, levando cada vez mais uma educação de qualidade e novidades. Conheci o tal do PBworks e a inclusão dele nas minha aulas, foi o grande diferencial, proporcionei um aprendizado autônomo, onde meus alunos podem ter acesso a suas produções de um lugar que não seja somente a escola, e poder levar estas produções ao alcance dos pais, em casa. Ainda tenho muito a acrescentar. Aluna A

As associações anteriores ((CPE COM) TIC) ligam-se, ainda, com um índice de 0,85, a categoria "referências ao trabalho dos professores-formadores e tutores", apontando que para as professoras-alunas do Curso, as conquistas alcançadas na formação com o uso das TICs são amparadas e estimuladas pelas interações com os professores-formadores e tutores.

Hoje, não é o fim,mas o início de uma novo ciclo. O início da nossa caminhada sem o PEAD. Mas o blog, com certeza vai continuar a nos acompanhar pela estrada a fora. Posso até imaginar as (nomes das professoras), dando uma vasculhadinha, de vez em quando, nos blogs a fim de poder saber notícias e de como essa trajetória mudou o rumo de educadoras, preparadas para um novo desafio: disseminar o uso das tecnologias em educação. Para muitos, pode 
parecer despedida, a nós do Curso a certeza que muitas coisas estão apenas começando. ATÉ A PRÓXIMA POSTAGEM... Aluna B

\title{
Supracategoria 2: A tomada de consciência das relações entre teorias e práticas pedagógicas e suas relações com as mudanças nas práticas requeridas pelo curso
}

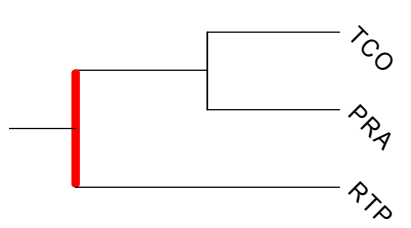

Nessa supracategoria destacamos uma importante associação entre as mudanças nas práticas pedagógicas requeridas pelo curso e as tomadas de consciência (TCO PRA, com índice de 0,99) principalmente relacionadas às relações entre as teorias estudadas no curso e as práticas em sala de aula ((TCO PRA) RTP), com índice de 0,90 . O exemplo a seguir ilustra essa associação.

\begin{abstract}
(...) Foi um semestre muito importante com várias atividades práticas onde as apliquei com meus alunos fazendo uma reflexão importante da minha prática pedagógica. Quanto tempo perdido com atividades que não chamavam muita atenção das crianças. A partir das atividades que fomos desenvolvendo e fui aplicando com meus alunos percebi o quanto cresci, pois comecei a levar em conta o conhecimento prévio, as experiências e a opinião dos educandos. Proporcionei um momento muito gostoso em sala de aula, quando trabalhei com a linha de tempo. Aluna $C$
\end{abstract}

Essa associação nos aponta para uma forte relação entre a experimentação de novas formas de trabalho em sala de aula (novas metodologias e tecnologias) propostas pelo curso e a tomada de consciência de novos relacionamentos entre a teoria (o que era estudado no curso) e as suas práticas, com enriquecimentos mútuos.

\section{Supracategoria 3: A tomada de consciência das relações entre a organização curricular e as aprendizagens}

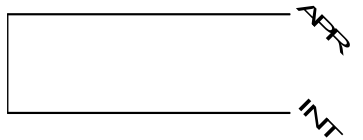

Nessa supracategoria encontramos uma associação (nível se similaridade 0,85) entre a tomada de consciência das relações entre a organização curricular, mediante as propostas de trabalhos das interdisciplinas e as aprendizagens de conteúdos ou conceitos, conforme mostra o exemplo:

No eixo VII, fizemos de início, um excelente exercício de observação na interdisciplina do Seminário Integrador. As professoras do SI sempre nos proporcionaram atividades criativas para que refletíssemos sobre a nossa prática docente, repensando a ação pedagógica, os conteúdos programáticos e os materiais de ensino usados como recurso nas aulas. (...) $O$ exercício de observação e formulação de hipóteses é uma atividade muito criativa para trabalhar com os alunos em sala de aula, pois desperta a curiosidade, desafiando-o a ter iniciativa frente a sua própria aprendizagem. (...). Aluna E

Essa associação nos leva a tomar como hipótese (o que deverá ser corroborado em outros estudos avaliativos) que, na visão das professoras-alunas do curso, as interdisciplinas cumpriram o seu papel de promover aprendizagem e favorecer as construções conceituais relativas aos diferentes campos do conhecimento abrangidos pelo curso. 


\subsection{Análise do grafo implicativo}

A análise das implicações entre as categorias de estudo vem a corroborar os resultados das similaridades, mostrando agora um sentido implicativo entre as categorias (variáveis). Se na análise das similaridades podemos afirmar que o comportamento das categorias é similar enquanto presença nas postagens, na análise implicativa introduzimos uma ideia de causalidade. O gráfico das implicações (Figura 2) apresenta os caminhos implicativos mais significativos:

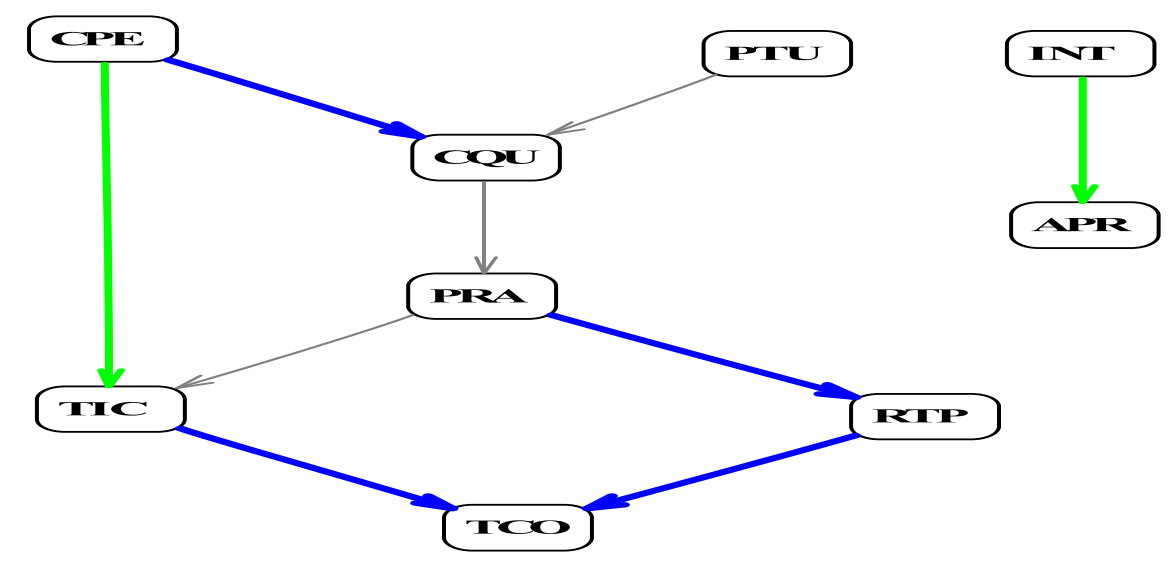

Figura 2 - Grafo de Implicações

\section{Caminho 1: $\mathrm{INT} \rightarrow \mathrm{APR}$}

O caminho implicativo 1 mostra que realizar registros no blog sobre as interdisciplinas cursadas durante os nove semestres do Curso implica em relatar a ocorrência de (em uma probabilidade implicativa de 0.90) aprendizagens de conteúdos específicos. Nos registros (blogs) também encontramos referências à organização interdisciplinar do curso como um fator de favorecimento das aprendizagens. Essa implicação corrobora os resultados da análise de similaridade quanto a constatações de tomadas de consciência das professoras-alunas das relações entre a organização curricular (interdisciplinaridade, integrações) e as aprendizagens, adicionando que as professoras-alunas consideram a organização interdisciplinar como favorecedora das aprendizagens.

\section{Caminhos 2, 3 e 4:}

Os caminhos implicativos 2, 3 e 4 partem das características do modelo do curso (CPE) e chegam às tomadas de consciência (TCO), mostrando que essas são favorecidas pelas características construtivistas-interacionistas do curso. No entanto, essa influência pode ocorrer segundo diferentes trajetos, conforme apresentamos a seguir.

\begin{tabular}{|l|l|l|}
\hline Caminho 2: & Caminho 3 & Caminho 4 \\
\hline $\mathrm{CPE} \rightarrow$ & $\mathrm{CPE} \rightarrow$ & $\mathrm{CPE} \rightarrow \mathrm{TIC} \rightarrow \mathrm{TCO}$ \\
$\mathrm{COM} \rightarrow \mathrm{PRA} \rightarrow \mathrm{RTP} \rightarrow \mathrm{TCO}$ & $\mathrm{COM} \rightarrow \mathrm{PRA} \rightarrow \mathrm{TIC} \rightarrow \mathrm{TCO}$ & \\
\hline
\end{tabular}

- O caminho 2 mostra uma implicação entre às características do modelo do Curso referenciadas pelas professoras-alunas levando-as a conquistas (mudanças nas 
concepções pedagógicas), sendo que essas mudanças, por sua vez, ocasionam ressignificações nas práticas pedagógicas em sala de aula (PRA $\rightarrow$ RTP) e o estabelecimento de novas relações entre teoria e prática, o que acaba por favorecer tomadas de consciência (em diferentes níveis) de influências do modelo do curso em mudanças nas suas concepções e práticas pedagógicas. (TCO).

- O caminho 3 mostra uma diferença do anterior, somente a partir das mudanças nas práticas pedagógicas em sala de aula (PRA) que podem levar para a implicação PRA $\rightarrow$ TIC, mostrando que as mudanças nas práticas pedagógicas com o uso das tecnologias em sala de aula é um dos caminhos para o favorecimento de tomadas de consciência (em diferentes níveis) de relações de implicação entre o modelo do curso e as mudanças nas suas concepções e práticas pedagógicas.

- O caminho 4 apresenta uma outra possibilidade de implicação mais direta das características do modelo de curso com o uso das tecnologias em sala de aula, favorecimento de tomadas de consciência (em diferentes níveis) das relações entre o modelo do curso e as mudanças nas suas concepções e práticas pedagógicas.

\section{Caminhos 5 e 6}

Estes caminhos implicativos partem do trabalho de interação dos professoresformadores e tutores (PTU) e chegam às tomadas de consciência (TCO), seguindo diferentes trajetos, conforme apresentamos a seguir.

\begin{tabular}{|l|l|}
\hline Caminho 5 & Caminho 6 \\
\hline $\mathrm{PTU} \rightarrow \mathrm{COM} \rightarrow \mathrm{PRA} \rightarrow \mathrm{RTP} \rightarrow \mathrm{TCO}$ & $\mathrm{PTU} \rightarrow \mathrm{COM} \rightarrow \mathrm{PRA} \rightarrow \mathrm{TIC} \rightarrow \mathrm{TCO}$ \\
\hline
\end{tabular}

- Os caminho 5 e 6 apresentam apenas uma mudança em relação aos caminho 2, 3 e 4 que é o ponto de partida. Os caminhos 5 e 6 especificam uma das características do modelo do curso que é a interação constante e intensiva dos professores-formadores, tutores e alunos implicando no alcance de conquistas e, no seguimento do caminho, implicando em novas relações entre teoria e prática (RTP) no caminho 5 e no uso das TICs na escola (TIC) no caminho 6 para, finalmente, implicar em tomadas de consciência das infuências do modelo do curso na sua formação.

\section{Considerações Finais}

É importante salientar a coerência dos resultados estatísticos qualitativos obtidos no que se refere às relações de similaridade e implicação, obtidas no tratamento dos dados submetidos ao software CHIC. As relações de similaridade são corroboradas e especificadas pelas relações de implicação, salientando as condições fundamentais ou as características do modelo de formação que alavancam processos de tomada de consciência dentro do contexto de formação de professores em serviço, na modalidade EAD.

Os resultados dos tratamentos estatísticos qualitativos apontam que o processo de tomada de consciência foi favorecido a partir de caminhos diferenciados, porém 
integrados, principalmente pelo projeto pedagógico do curso (modelo construtivistainteracionista) e pelo uso intensivo das tecnologias no curso e nas atividades desenvolvidas nas salas de aula das professoras-alunas.

Tomando como ponto de partida (caminho 2) os pressupostos fundamentais do PEAD (interação constante entre professoras-alunas, professores-formadores e tutores, estrutura interdisciplinar e a relação teoria-prática etc.) identificamos que essas características do modelo de formação constituíram-se em fatores desencadeadores de tomadas de consciência relacionadas aos efeitos dessa formação na reconstrução das concepções pedagógicas.

As professoras-alunas também (1) estabeleceram relações (mediante tomadas de consciência) entre a formação vivenciada e a reconstrução/recriação de ideias e formas de atuação nos seus espaços de docência e (2) introduziram ou reformularam a concepção e os usos das tecnologias na sua sala de aula. Também foi constatado que a proposta de trabalho interativo desenvolvido por professores-formadores e tutores (caminho 3) atuaram como um elemento disparador desses processos de tomadas de consciência.

Outro resultado interessante refere-se ao papel das interdisciplinas (estrutura curricular do curso) que são consideradas pelas professoras-alunas do curso como um fator favorecedor das aprendizagens, seja pelos conteúdos abordados, seja pela metodologia interativa e problematizadora utilizada no Curso.

Os resultados do estudo reforçam positivamente as observações realizadas no dia a dia do curso. Nos webfólios das professoras-alunas é possível ver que as tecnologias cumpriram um papel fundamental, tanto na formação quanto nas suas práticas docentes. Se no início do curso as tecnologias mostraram-se como obstáculos às ações, essas se tornaram grandes aliadas na medida da sua superação e abriram muitas possibilidades de interações e realizações durante o curso e importantes inovações nos seus espaços de docência.

\section{Referências}

AG ALMOULOUD, S. L'ordenateur: outil d'aide à l'apprentissage et de traitement d'analyse de données didactiques. Thèse de L'Université de Rennes I. 1992

BORDAS, M.; NEVADO, R.A.; CARVALHO, M.J.S.. Formação de professores: pressupostos pedagógicos do curso de Licenciatura em Pedagogia/EAD. Informática na Educação, Porto Alegre, v. 8, n. no. 1, p. 143-167, 2005.

C.H.I.C. Classification Hierárquique, Implicative et Cohérsive. Version Windows, 2007. (software)

GRAS, R. L'analyses des donnés : une méthodologie de traitement de questions de didactique. Recherches en Didactiques Mathématiques, vol 12-1. 1992

NEVADO, R. A.; CARVALHO, M.J.S.; MENEZES, C.S.. Inovações na formação de professores na modalidade a distância. ETD: Educação Temática Digital, v. 10, p. 373-393, 2009.

PIAGET, J. A Tomada de consciência. São Paulo: Melhoramentos, 1977.

PIAGET, J. Fazer e compreender. São Paulo: Melhoramentos, 1978. 